\title{
Topics
}

\section{Space Weather Monitoring and Forecasting Activity in NICT}

\author{
By Tsutomu Nagatsuma, Shinichi Watari and Ken T. Murata
}

Applied Electromagnetic Research Institute, National Institute of Information and Communications Technology, Koganei, Japan

(Received June 28th, 2011)

\begin{abstract}
Disturbances of Space environment around the Earth (geospace) is controlled by the activity of the Sun and the solar wind. Disturbances in geospace sometimes cause serious problems to satellites, astronauts, and telecommunications. To minimize the effect of the problems, space weather forecasting is necessary. In Japan, NICT (National Institute of Information and Communications Technology) is in charge of space weather forecasting services as a regional warning center of International Space Environment Service. With help of geospace environment data exchanging among the international cooperation, NICT operates daily space weather forecast service every day to provide information on nowcasts and forecasts of solar flare, geomagnetic disturbances, solar proton event, and radio-wave propagation conditions in the ionosphere. For prompt reporting of space weather information, we also conduct our original observation networks from the Sun to the upper atmosphere: Hiraiso solar observatory, domestic ionosonde networks, magnetometer \& HF radar observations in far-east Siberia and Alaska, and south-east Asia low-latitude ionospheric network (SEALION). ACE (Advanced Composition Explorer) and STEREO (Solar TErrestrial RElations Observatory) real-time beacon data are received using our antenna facilities to monitor the solar and solar wind conditions in near real-time. Our current activities and future perspective of space weather monitoring and forecasting will be introduced in this report.
\end{abstract}

Key Words: Space Weather, Monitoring, Forecasting, Simulation, Data Analysis

\section{Introduction}

Disturbances in space environment around the Earth (geospace) are controlled by the activity of the Sun and the solar wind. The disturbances in geospace sometimes cause serious problems to satellites, astronauts, navigations, and telecommunications. To minimize the effect of these problems, space weather forecasting is very important and necessary. In this paper, current conditions and future direction of space weather forecasting are introduced.

\subsection{Regional warning center of ISES (RWC Tokyo)}

NICT is responsible for Japanese operational space weather forecast. Every day, we have a forecaster's meeting at 14:30 JST (See Fig. 1) to determine the current condition and future progress of solar, geomagnetic, and ionospheric activities.

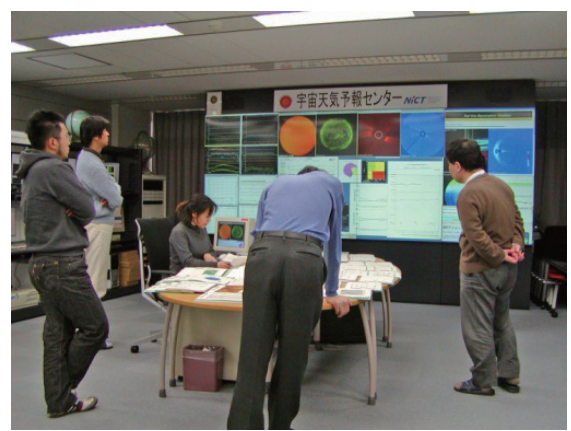

Fig. 1. Forecaster's meeting at 14:30 JST.

At beginning, the space weather forecasting started as forecasting of short-wave propagation conditions. In 1950's, to improve the reliability of long-distance communication by short-wave, the effects of solar activity in the ionosphere had been studied in detail ${ }^{1)}$. The International URSIgram and World Days Service (IUWDS) was formed in 1962 as a combination of the former International World Days Service, initiated in 1959 as part of the IGY, and the former URSI Central Committee of USRIgrams which initiated rapid international data interchange services in 1928. After 1996, IUWDS changed the name as International Space Environment Service (ISES). ISES is an international organization for exchanging space weather information and observation data for each area. NICT takes a role of regional warning center (RWC Tokyo) of ISES (Fig. 2).

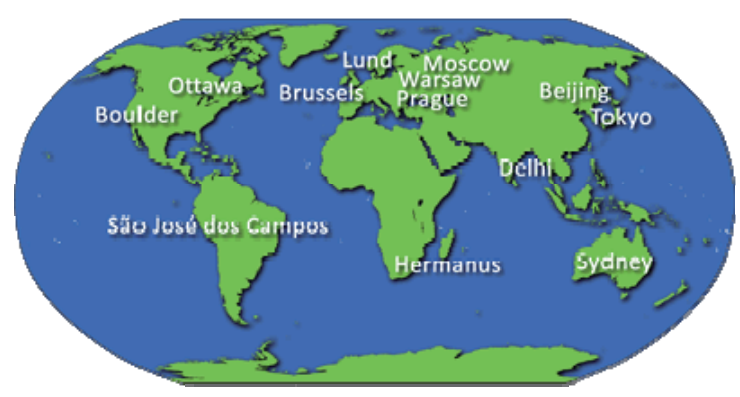

Fig. 2. Locations of the 13 regional warning centers (RWC) of ISES.

\subsection{WDC for ionosphere}

To archive and distribute data collected from the observational program of the 1957 - 1958 International Geophysical Year (IGY), World Data Center (WDC) system was established under ICSU (International Council for Science). In Japan, several organizations had interest about WDC. As a result, WDC in Japan is operated by each 
organization with each subject. In case of NICT, we have been operating WDC for Ionosphere since 1957. We are archiving mainly ionospheric vertical soundings of four Japanese and 141 worldwide stations. Further we are archiving the following items of ionospheric data. Ionospheric vertical soundings, topside soundings, oblique incidence soundings absorption, ionospheric drifts and backscatter, Whistlers and VLF, Atmospheric Radio Noise (See Fig. 3). Recently, a new ICSU World Data System (WDS) has been created in 2008. NICT will play a role of International Programme Office.

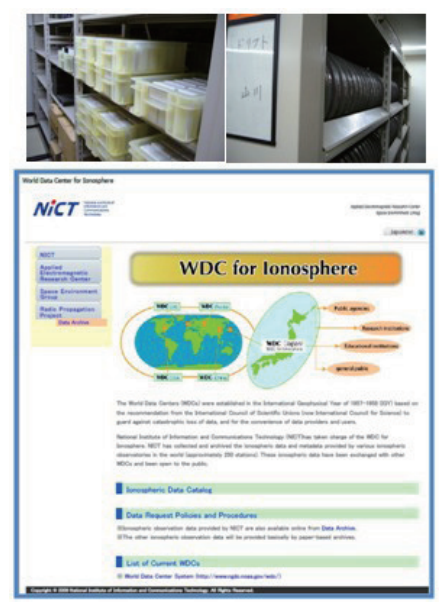

Fig. 3. (Top) Archived media (tape, paper) in WDC for Ionosphere. (Bottom) The Web page of WDC for Ionosphere.

\section{Information Service for Space Weather Forecast}

Information service is one of the key elements of space weather forecasting, because forecasting activities should be provided widely via the information service. We have been providing forecasting information and online database of space weather monitoring via internet for a long time. Fig. 4 is one of the latest content of space weather news via intenet.

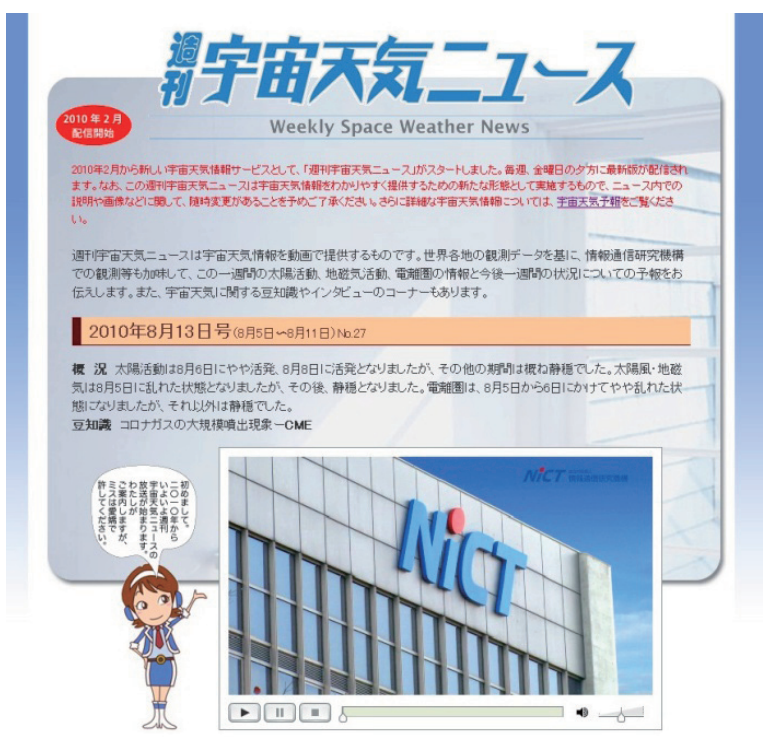

Fig. 4. The web page for weekly space weather news. Movies of weekly space weather news are being distributed from this page (http://www.seg.nict.go.jp/wsw/).

\section{Space Weather Monitoring Network (NICT-SWM)}

To understand the current conditions of space environment, network of observations from the Sun to the Earth's upper atmosphere is important. We have constructed comprehensive ground-based networks for space weather monitoring around the Japanese meridian from the polar region to the equatorial region for space weather operation and research (See Fig. 5). Overview of this space weather monitoring network (NICT-SWM) are introduced in this section

\section{NICT Space Weather Monitoring Networks (NICT-SWM)}

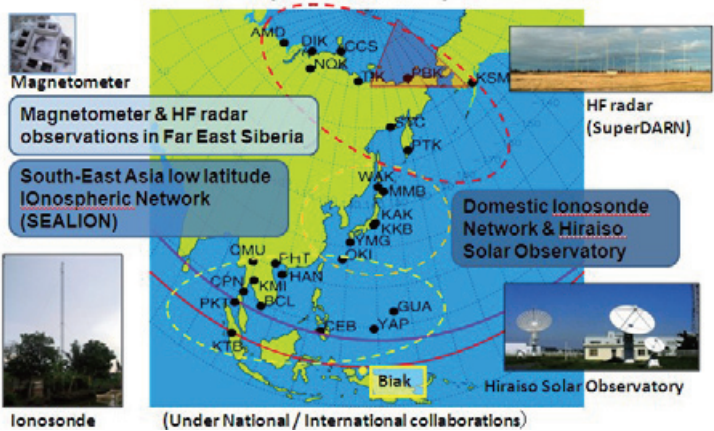

Fig. 5. NICT's space weather monitoring networks (NICT-SWM).

\subsection{Magnetometer networks and HF radar at King Salmon, Alaska}

Magnetic field variations are fundamental parameters in geospace disturbances. Current system flowing in the ionosphere and magnetosphere can be estimated from these variations. We have operated 5 magnetometers at Japanese meridian sector by ourselves. To monitor the geomagnetic activities in auroral latitude of Siberian area corresponds to the footprint of Japanese geostationary satellite, we have operated international Russia-Japan-USA project, RapidMag (Russian Auoral and Polar Ionospheric Disturbance Magnetometers) ${ }^{2}$. We have also participated INTERMAGNET, which is an international consortium of magnetometer data.

Magnetospheric plasma convection is a major manifestation of the solar wind and the magnetosphere. To monitor plasma drift velocities in the auroral and sub-auroral ionosphere, we have been operating HF radar at King Salmon, Alaska, USA. The purpose of this radar is to monitor plasma drift velocities in the auroral and sub-auroral ionosphere. We have joined SuperDARN (Dual-Auroral Radar Network). Because SuperDARN has many HF radars not only at Arctic and Antarctic area, but also for mid-latitude region, global dynamics of plasma convection can be monitored by this network.

3.2. Domestic ionosonde networks and hiraiso solar observatory

We have four ionosondes in Japan and one ionosonde in Syowa station, Antarctica. Routine vertical sounding by these ionosondes are operating every 15 minutes. We had more than fifty years of ionospheric observation.

Radio and optical solar telescopes are installed at Hiraiso Solar Observatory. We have $\mathrm{H}$-alpha optical telescope, and a widest frequency band of solar radio spectrograph, which we 
call HiRAS (Hiraiso Radio Spectrograph).

We also have several antenna facilities to receive spacecraft data. Currently, we are receiving ACE and STEREO near-real time data in routine bases.

\subsection{South-East Low-Latitude Ionospheric Networks (SEALION)}

To monitor and to study on ionospheric disturbances (e.g. equatorial plasma bubble, equatorial spread-F) occurred in the equatorial region by using ionospheric and geomagnetic field observations, we have started the operation of South-East Asia Low-Latitude Ionospheric Network (SEALION). We have six ionosondes, four GPS receivers, two GPS scintillation monitors, two magnetometers, and one all-sky imager.

\section{NICT's Real-Time Space Weather Simulator}

The forecasting of space weather is being developed with following the development stages of terrestrial weather forecasting. It is often said that space weather forecasting is 50 years behind the terrestrial weather forecasting, because there is no operational numerical forecast scheme for space weather forecasting ${ }^{3)}$. However, several real-time simulators for space weather forecast are running as an advanced research and development.

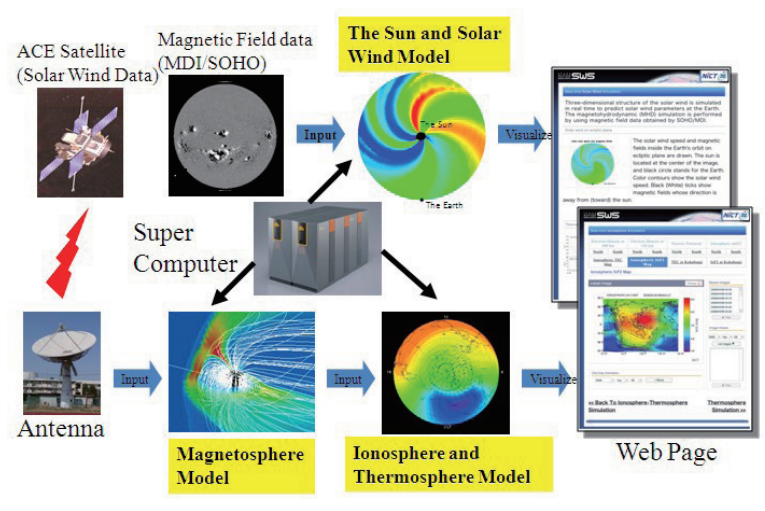

Fig. 6. Flow diagrams of NICT's real-time space weather simulator.

Fig. 6 shows flow diagrams of real-time space weather simulator developed by NICT. A diagram for the Sun and the solar wind model is shown on the top. The input parameters for this model are derived from near real-time magnetic field data of the Sun's photosphere from Solar and Helisopheric Observatory (SOHO). A diagram for the magnetosphere model, the ionosphere, and the thermosphere model is shown on the bottom. The input parameters for the magnetosphere model are derived from real-time solar wind data received from Advanced Composition Explorer (ACE). After the calculations of the magnetosphere model, the ionosphere and thermosphere model is calculated based on the results of the magnetosphere model. We have our own node of middle-class supercomputer (SX-8) to calculate the real-time output of space weather forecast. The results of these real-time space weather simulators are provided via Web pages (http://www2.nict.go.jp/y/y223/simulation/realtime/home.html ) .

\section{Interaction with Users}

To understand the needs of space weather users, we sometimes have a forum called, "Space Weather User's Forum". In every forum, more than 50 peoples are joined (See Fig. 7).

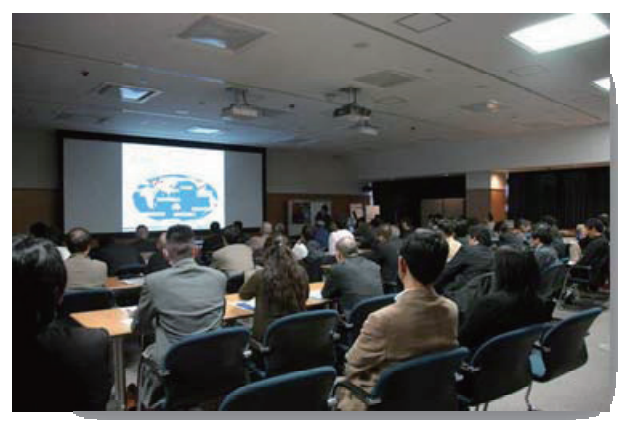

Fig. 7. Space Weather User's Forum on Dec. 21, 2009.

We have provided tutorial talks about space weather phenomena and how to interpret the data and plots shown in our information services. The followings are three major requests from users;

1. Nowcast / Forecast of solar / geomagnetic activity

2. Nowcast / Forecast of space environment around GEO / LEO

3. Nowcast / Forecast of ionospheric scintillation and TEC map over Japan

\section{Summary}

As we described in the previous sections, we are operating daily space weather forecasting and world data center for ionosphere. Space weather monitoring network and real-time space weather simulator are also operated. We are collecting practical needs of users / customers with educating space weather phenomena and its effect. Also, we start building a close relationship with Japanese Space Exploration Agency (JAXA) and Japanese Meteorological Agency (JMA) now.

\section{Acknowledgments}

Near-real time data acquisition from ACE and STEREO are supported by NOAA and NASA.

\section{References}

1) Nishida, A.: The rise of space weather research in Japan, Space Weather, 8 (2010), S04001, doi: 10.1029/2009SW000528.

2) Takahashi, K., Meng, C. I., Kamei, T., Kikuchi, T. and Kunitake, M.: Near-real-time auroral electrojet index: An intenational collaboration makes rapid delivery of auroral electrojet index, Space Weather, 2 (2004), S1 103, doi: 10.1029/2004SW000116.

3) Den, M., Tanaka, T., Fujita, S., Obara, T., Shimazu, H., Amo, H., Hayashi, Y., Nakano, E., Seo, Y., Suehiro, K., Takahara, H. and Takei, T.: Real-time Earth magnetosphere simulator with three-dimensional magnetohydrodynamic code, Space Weather, 4 (2006), S06004, doi: 10.1029/2004SW000100. 